\title{
Research on Identification of Damage Development Mode of Rural Highway Asphalt Pavement Structure
}

\author{
Han Mengdi ${ }^{1}$, Fu Yihang ${ }^{2}$ \\ 1. Shenyang Jianzhu University, Shenyang, 110000, China \\ 2. Liaoning Civil Defense Architectural Design and Research Institute Co., Ltd. , Shenyang, \\ 110000, China \\ E-mail:136033217@qq.com
}

\begin{abstract}
According to the damage condition of asphalt pavement of rural roads in Liaoning Province, five development modes of asphalt pavement damage were proposed to determine the damage condition of asphalt pavement in the investigation section. The trapezoidal and semi-trapezoidal membership functions are used to construct the membership matrix, and the fuzzy comprehensive evaluation model is established, and the weight vector of each factor is determined. Finally, fuzzy mathematics is used to determine the stage of the general development period of the structural damage of the road segment. The research results have certain guiding significance for the management and maintenance of rural road asphalt pavement in Liaoning Province.

Key words: damage condition; development mode of asphalt pavement damage; asphalt pavement; membership function; fuzzy mathematics
\end{abstract}

\section{Introduction}

Due to the important position of the main road in transportation, people have invested more energy in the establishment of the investigation and evaluation system for the damage condition of the asphalt pavement of the main road in China, and the assessment of the damage condition of the asphalt pavement of the rural road is still in its infancy. China's rural road construction and management started late, lack of experience, data collection period is very short and external data collection is not comprehensive, so no complete database has been established. In the assessment of the damage condition of the asphalt pavement of rural roads, if the road surface damage assessment system of the roadway is completely copied, it is inconsistent with the actual situation, resulting in waste of funds. It is necessary to reduce the damage condition of asphalt pavement structure for the characteristics of less traffic flow in rural roads, less vehicle load and low vehicle speed.

Liaoning Province is located in the south of the northeastern part of China, with distinct regional characteristics and climatic conditions. The change of environmental parameters has a great influence on the mechanical response and service function of the pavement structure ${ }^{[1]}$. These factors have led to a rapid decline in the quality of the road surface after the rural roads are put into use. And the road damage condition contains many factors, and the damage is different, and accurate quantitative evaluation cannot be given. It can only explain how much damage it belongs to ${ }^{[2]}$.

This paper proposes five kinds of damage modes in the general development period of rural road asphalt pavement structure damage in accordance with the actual situation in Liaoning Province. The fuzzy mathematics method is used to evaluate the pavement damage condition, and try to apply the basic theory of model recognition in fuzzy set theory to the identification of pavement damage. The judgment results have reference significance for guiding the maintenance and management of rural roads in Liaoning Province.

\section{Damage development mode of rural highway asphalt pavement structure}

Through the field investigation and drilling core sampling of 300 rural road asphalt pavements in various cities and counties in Liaoning Province during the three years from 2016 to 2018, it is concluded that the type and degree of pavement diseases correspond to the damage of the pavement surface layer and the base layer. The five typical damage modes for the general development of the asphalt pavement structure of rural roads in Liaoning Province are presented in table 1 . 
Table 1 Rural highway asphalt pavement structure damage general development period model

$\begin{array}{ccc}\begin{array}{c}\text { Damage modes } \\ \text { stage }\end{array} & \text { Damage } & \text { Damage } \\ \text { condition } & \text { feature }\end{array}$

I - Typical
pattern of
transverse joint
development

II - Typical mode of longitudinal and transverse seam development

III- Typical
pattern of block
crack
development
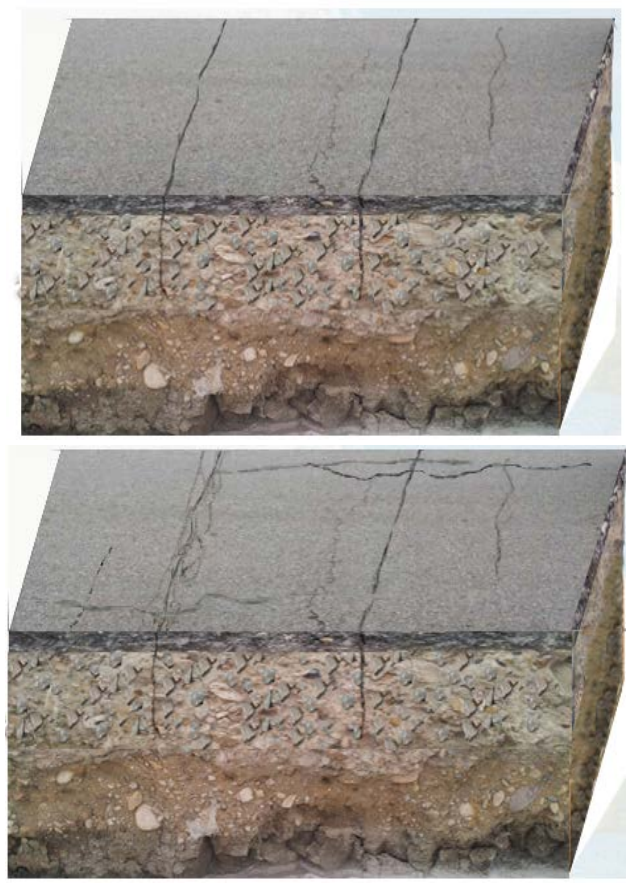

The lateral cracks in the asphalt surface gradually developed to a serious extent and began to appear as joints. The number of transverse cracks in a hundred meters is between 7 and 15. Longitudinal cracks begin to appear at the wheel track. The length of the longitudinal slit accounts for $<0.3$ of the total length of the route. The road surface has no obvious deformation and the flatness is good. The vehicle can travel safely at the design speed and the base material is partially damaged.

The transverse and longitudinal joints are further developed into block fractures, and the block crack area accounts for $<0.3$ of the total road surface area. Moderate road surface deformation at the crack. The vehicle barely maintains the design speed, the base layer is

damaged, and the local failure occurs.
IV - Typical pattern of crack formation
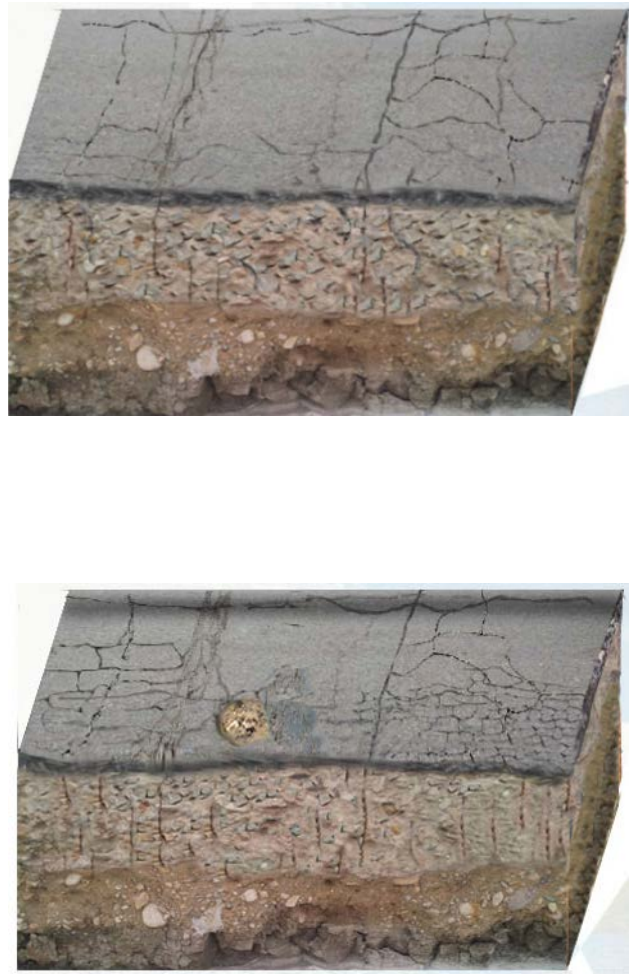

Asphalt surface block cracks gradually develop into cracks, the block crack area accounts for about 0.3 of the total pavement area, and the cracked area accounts for $<0.4$ of the total pavement area, accompanied by diseases such as ruts and pits. The road surface is obviously deformed and the flatness is low. Vehicles cannot travel safely at the design speed, and most of the base layers fail. 


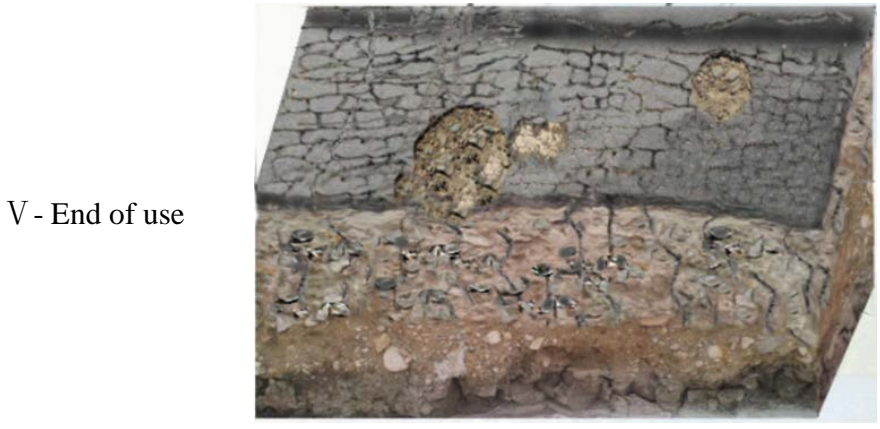

There are a large number of different degrees of transverse seams, longitudinal joints, block cracks, cracks, ruts, pits and other diseases in the asphalt surface layer. The cracked area is half of the total pavement area. The road surface is severely deformed and the flatness is poor. The vehicle cannot meet the driving requirements and the base layer is completely ineffective.

\section{Method for identifying damage development pattern of rural road asphalt pavement}

Fuzzy pattern recognition is a pattern recognition method based on fuzzy mathematics theory. The fuzzy theory holds that an element in a fuzzy set does not belong to a certain set $100 \%$, but belongs to the set in a certain proportion. Unlike traditional collection theory, an element either belongs to or does not belong to the definition of the collection. More in line with many vague practical problems in reality, the description is more simple and reasonable. The emergence of fuzzy mathematics allows one to simulate the activities of the human nervous system and describe the extent to which patterns belong to a certain class. Therefore, fuzzy mathematics has been applied in model recognition ${ }^{[3]-[5]}$.

Therefore, we try to apply the basic theory of model recognition in fuzzy set theory to the identification of the damage condition of rural road asphalt pavement.

\subsection{Factor analysis}

During the use of asphalt pavement, under the repeated action of driving load and natural factors, the pavement will have various damages. Asphalt pavement damage can be divided into four types: cracks, deformations, friability and other types. Various types of damage have different manifestations ${ }^{[6]}$. The road grade of rural roads is low, the base is large, the mileage is long, and the oil-borne diseases are less likely to occur on rural road asphalt pavements. All the disease classifications are considered for analysis in the road surface disease investigation. In view of the above, the main factors that need to be considered in the pattern of road surface damage identification are ${ }^{[7]-[8]}$ :
(1)Transverse crack
(2)Vertical crack
(3)Block crack
(4)Crack
(5)Pits
(6)Deformation (including rutting, subsidence)

According to the results of the route survey, the six influencing factors can be initially identified as the basis for further analysis and evaluation. Establish an indicator table for evaluating the damage condition of asphalt pavement as shown in table 2.

Table 2 Asphalt pavement damage condition evaluation factor indicator

\begin{tabular}{|c|c|c|c|c|c|c|}
\hline \multicolumn{2}{|c|}{ Type of disease } & I & II & III & IV & V \\
\hline \multirow{3}{*}{$\begin{array}{c}\text { Transverse crack } \\
\text { (number of pieces / } 100 \text { meters) }\end{array}$} & Only cracks & $\leq 7$ & $\leq 15$ & $>15$ & - & - \\
\hline & Appears block cracks & 0 & $\leq 7$ & $\leq 15$ & $>15$ & - \\
\hline & Appears cracks & 0 & 0 & $\leq 7$ & $\leq 15$ & $>15$ \\
\hline \multirow{3}{*}{$\begin{array}{c}\text { Vertical crack } \\
\text { (total length / length of link) }\end{array}$} & Only cracks & 0 & $\leq 0.3$ & $\leq 0.7$ & $>0.7$ & - \\
\hline & Appears block cracks & 0 & 0 & $\leq 0.3$ & $\leq 0.7$ & $>0.7$ \\
\hline & Appears cracks & 0 & 0 & 0 & $\leq 0.7$ & $>0.7$ \\
\hline \multicolumn{2}{|c|}{$\begin{array}{c}\text { Block crack } \\
\text { (area / total road surface area) }\end{array}$} & 0 & 0 & $\leq 0.3$ & $\leq 0.6$ & $\leq 1$ \\
\hline \multicolumn{2}{|c|}{$\begin{array}{c}\text { Cracking } \\
\text { (area / total road surface area) }\end{array}$} & 0 & 0 & 0 & $\leq 0.4$ & $\leq 1$ \\
\hline \multicolumn{2}{|c|}{$\begin{array}{c}\text { Pits } \\
\text { (area / total road surface area) }\end{array}$} & 0 & 0 & $\leq 0.01$ & $\leq 0.05$ & $\leq 0.3$ \\
\hline \multicolumn{2}{|c|}{$\begin{array}{c}\text { Deformation } \\
\text { (degree / mm) }\end{array}$} & 0 & $\leq 5$ & $\leq 10$ & $\leq 40$ & $>40$ \\
\hline
\end{tabular}




\subsection{The application principle of fuzzy mathematics}

\subsubsection{Establishment of membership function}

The evaluation factor $u_{\mathrm{i}}$ belongs to the general membership function form of the $j$-level rural road asphalt pavement structure damage. See equation 1.

$$
r_{i j}= \begin{cases}0, & c_{i} \leq s_{i, j-1} \text { or } c_{i} \geq s_{i, j+1} \\ \frac{c_{i}-s_{i, j-1}}{s_{i, j}-s_{i, j-1}}, & s_{i, j-1}<c_{i}<s_{i, j} \\ \frac{s_{i, j+1}-c_{i}}{s_{i, j+1}-s_{i, j}}, & s_{i, j-1}<c_{i}<s_{i, j} \\ 1, & c_{i}<s_{i, j}\end{cases}
$$

In the formula: $r_{\mathrm{ij}}$ Evaluation factor $i$ to $j$-level damage mode membership

$c_{\mathrm{i}}$-Evaluation factor $i$ value

$s_{\mathrm{ij}}$ _Evaluation factor $i$ level $j$ standard

\subsubsection{Univariate evaluation matrix}

From the above calculation process, a single factor fuzzy evaluation set corresponding to each factor is obtained.

$$
\begin{gathered}
R_{1}=\left(r_{11}, r_{12}, \cdots, r_{1 m}\right) \\
R_{2}=\left(r_{21}, r_{22}, \cdots, r_{2 m}\right) \\
\vdots \\
R_{n}=\left(r_{n 1}, r_{n 2}, \cdots, r_{n m}\right)
\end{gathered}
$$

If there are $m$ evaluation objects (parameters) and $n$ levels of damage status patterns, the following $m \times n$ fuzzy matrices can be constructed.

$$
R=\left(\begin{array}{c}
r_{11}, r_{12}, \cdots, r_{1 m} \\
r_{21}, r_{22}, \cdots, r_{2 m} \\
\vdots \\
r_{n 1}, r_{n 2}, \cdots, r_{n m}
\end{array}\right)
$$

\subsubsection{Determination of single parameter weight (index value)}

In general, the degree of importance of each damage situation is different. Therefore, each factor $u_{\mathrm{i}}$ is given a corresponding weight $a_{\mathrm{i}}(i=1,2, \ldots n)$, and the method for determining the weight set $\mathrm{A}, a_{\mathrm{i}}$ is as shown in equation 2 .

$$
\omega_{i}=\frac{C_{i}}{S_{i}}
$$

In the formula: $\omega_{\mathrm{i}}$ : The weight of the parameter $i$ (index value)

$c_{\mathrm{i}}$ : Measured value of parameter $i$

$s_{\mathrm{i}}$ : The arithmetic mean of the standard values of damage status at all levels of parameter $i$

\subsubsection{Calculate the weight of a single parameter}

For the fuzzy operation, the weights of the parameters are normalized to obtain the weight of the parameters as shown in equation $3^{[9]}$.

Finally, form a weight set

$$
a_{i}=\frac{\omega_{i}}{\sum_{i=1}^{n} \omega_{i}}=\frac{\frac{c_{i}}{S_{i}}}{\sum_{i=1}^{n} \frac{c_{i}}{s_{i}}}
$$

$$
A=\left\{a_{1}, a_{2}, \cdots, a_{m}\right\}
$$




\subsection{Comprehensive evaluation}

The above $A$ (weight set of parameter composition) and $R$ (the fuzzy matrix composed of evaluation objects and evaluation criteria), that is, the equation (1) and the equation (2) are combined, and $A \times R$ is shown in equation $4^{[10]}$.

$$
A \times R=\left(a_{1}, a_{2}, \cdots, a_{m}\right)\left(\begin{array}{c}
r_{11}, r_{12}, \cdots, r_{1 m} \\
r_{21}, r_{22}, \cdots, r_{2 m} \\
\vdots \\
r_{n 1}, r_{n 2}, \cdots, r_{n m}
\end{array}\right)=\left(b_{1}, b_{2}, \cdots, b_{m}\right)
$$

This result is the degree of membership corresponding to each road damage condition mode. According to the principle of maximum membership degree, the damage condition mode corresponding to the largest one is taken as the comprehensive damage condition mode of the road section. If there are two numbers the same, then the two of the two numbers are the larger ${ }^{[7]}$.

\section{Instance application}

Taking the Jianhuang line of Benxi City, Liaoning Province as an example. The Jianhuang yellow line starts from the Dongshan Temple of the alkali plant, the pile number is 0.000 , and it stops at Huangbao, and the pile number is 5.762. The survey was conducted in 2017.5.11, the road width was $6 \mathrm{~m}$, and the length of the research section was $1000 \mathrm{~m}$. The Jianhuang line surface is shown in figure 1 and figure 2. Field surveys of pavement diseases are shown in table 3 .

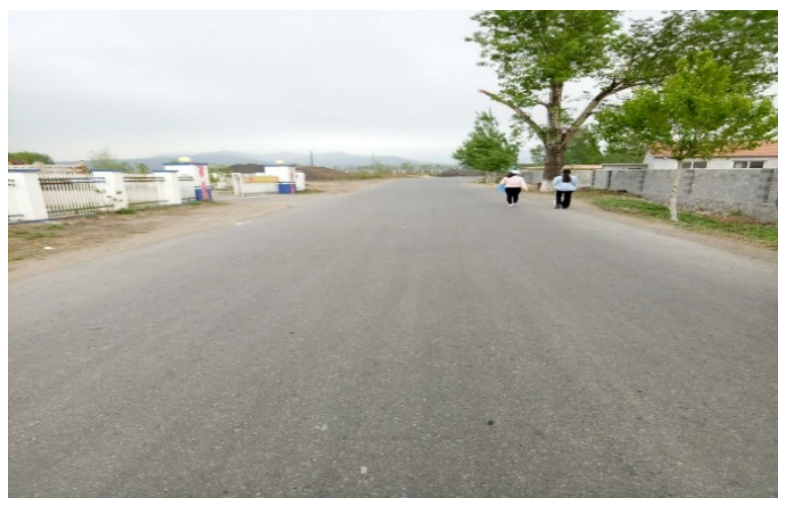

Fig.1 The Jianhuang line (1)

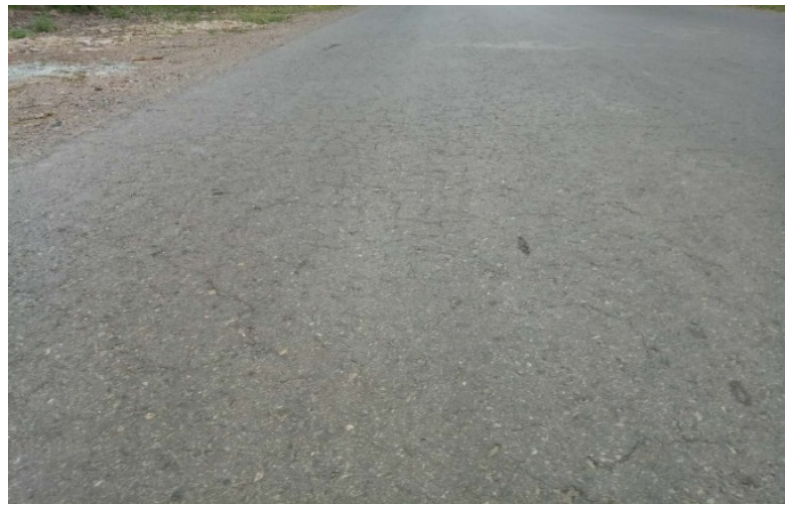

Fig.2 The Jianhuang line (2)

Table 3 Survey of diseases on the Jianhuang line

\begin{tabular}{|c|c|c|c|c|c|c|c|c|c|}
\hline \multirow[t]{2}{*}{ Station number } & \multirow{2}{*}{$\begin{array}{c}\text { Transverse } \\
\text { crack } \\
\text { ( pieces) }\end{array}$} & \multirow{2}{*}{$\begin{array}{c}\text { Vertical } \\
\text { crack } \\
(\mathrm{m})\end{array}$} & \multicolumn{2}{|c|}{$\begin{array}{c}\text { Block crack } \\
\left(\mathrm{m}^{2}\right)\end{array}$} & \multicolumn{3}{|c|}{$\begin{array}{l}\text { crack } \\
\left(\mathrm{m}^{2}\right)\end{array}$} & \multirow{2}{*}{$\begin{array}{l}\text { Pits } \\
\left(\mathrm{m}^{2}\right)\end{array}$} & \multirow{2}{*}{$\begin{array}{l}\text { Deformation } \\
\quad(\mathrm{mm})\end{array}$} \\
\hline & & & Mild & Severe & Mild & Moderate & Severe & & \\
\hline $\mathrm{k} 0+500-\mathrm{k} 0+600$ & 7 & - & 74 & 14 & - & - & - & - & - \\
\hline $\mathrm{k} 0+600-\mathrm{k} 0+700$ & 9 & 10 & 63 & 25 & - & - & - & - & - \\
\hline $\mathrm{k} 0+700-\mathrm{k} 0+800$ & 10 & 5 & 55 & - & - & - & - & - & 3 \\
\hline $\mathrm{k} 0+800-\mathrm{k} 0+900$ & 12 & 一 & 33 & - & - & - & - & - & 2 \\
\hline $\mathrm{k} 0+900-\mathrm{k} 1+000$ & 7 & 20 & 7 & 15 & - & - & - & - & - \\
\hline $\mathrm{k} 1+000-\mathrm{k} 1+100$ & 12 & 7 & 24 & 85 & - & - & - & - & 2 \\
\hline $\mathrm{k} 1+100-\mathrm{k} 1+200$ & 14 & 15 & 47 & - & - & - & - & - & - \\
\hline $\mathrm{k} 1+200-\mathrm{k} 1+300$ & 12 & - & 18 & - & - & - & - & - & - \\
\hline $\mathrm{k} 1+300-\mathrm{k} 1+400$ & 6 & - & 5 & - & - & - & - & - & - \\
\hline $\mathrm{k} 1+400-\mathrm{k} 1+500$ & 7 & - & 30 & - & - & - & - & - & - \\
\hline total & 96 & 57 & 356 & 139 & - & - & - & - & 7 \\
\hline $\begin{array}{c}\text { Mean/per } 100 \\
\text { meters }\end{array}$ & 9.6 & 5.7 & 35.6 & 13.9 & - & - & - & - & 0.7 \\
\hline
\end{tabular}

In order to evaluate the damage condition of this section, the fuzzy state method was used to evaluate the damage condition of this section. The transverse crack, vertical crack, block crack, crack, pit and pavement deformation are used as evaluation parameters. The specific calculation process is as follows:

\subsection{Calculate the membership of each evaluation parameter}


The data in table 3 is taken into equation 1 , and the calculation results are shown in table 4

Table 4 The degree of membership of evaluation parameters for the Jianhuang line surface damage

\begin{tabular}{cccccc}
\hline Parameter & I & II & III & IV & V \\
\hline Transverse crack & 0 & 0.675 & 0.325 & 0 & 0 \\
Vertical crack & 0 & 0.81 & 0.19 & 0 & 0 \\
Block crack & 0 & 0.7 & 0.3 & 0 & 0 \\
Crack & 0.33 & 0.33 & 0.33 & 0 & 0 \\
Pits & 0.5 & 0.5 & 0 & 0 & 0 \\
Deformation & 0.86 & 0.14 & 0 & 0 & 0 \\
\hline
\end{tabular}

The membership degree of the pavement damage condition evaluation parameter corresponds to the fuzzy matrix composed of five kinds of pavement damage modes.

$$
R=\left(\begin{array}{lllll}
0 & 0.675 & 0.325 & 0 & 0 \\
0 & 0.81 & 0.19 & 0 & 0 \\
0 & 0.7 & 0.3 & 0 & 0 \\
0.33 & 0.33 & 0.33 & 0 & 0 \\
0.5 & 0.5 & 0 & 0 & 0 \\
0.86 & 0.14 & 0 & 0 & 0
\end{array}\right)
$$

\subsection{Calculate the weight value of each parameter}

Bring the data in table 4 into equation 2 and get $\omega_{1}==0.78 ; \omega_{2}=0.101 ; \omega_{3}=0.143 ; \omega_{4}=0 ; \omega_{5}=0 ; \omega_{6}=0.002$ 。

Then the resulting weight value is brought into equation 3 , and the weight is normalized and get $A=$ $(0.76,0.098,0.139,0,0,0.003)$

\subsection{Fuzzy evaluation calculation}

Bring $R$ and $A$ into equation 4 and get

$B=R^{*} A=(0.003,0.69,0.307,0,0)$

According to the composite operation result and the maximum membership degree principle of the fuzzy matrix, it is known that the road surface damage condition of the investigation section is the most likely to belong to the mode II, and is positively developed in the mode III.

\subsection{Evaluation test}

The core is taken in the Jianhuang line, and the structural damage degree of the road surface is judged according to the state of the core sample taken out. A comparison test is made with the degree of road damage caused by fuzzy evaluation to determine whether the fuzzy evaluation result is accurate.

The Jianhuang line has a total of three cores, and one core are taken in the transverse cracks. One core is obtained in the pavement structure, and one core is taken in the block crack.

(1) Core sample 1

The core is taken at the lateral reflection crack of the road surface and recorded as the core sample 1 . The original road surface condition at the core and the core sample and core pit taken are shown in figures 3(a) (c). The surface core sample is split at the transverse crack. The core layer of the base layer is broken, and agglomerates are locally present. Most of the pellets are out of position. The inner wall of the core pit is basically smooth. It can be seen that the base material is partially damaged and conforms to the typical characteristics of mode II.

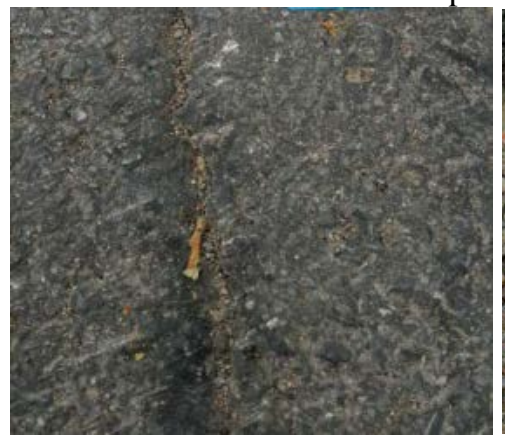

Fig.3 (a) Core sample 1 original pavement

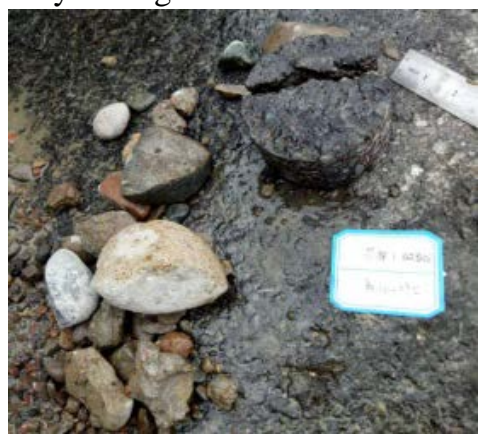

Fig.3 (b) Core sample 1

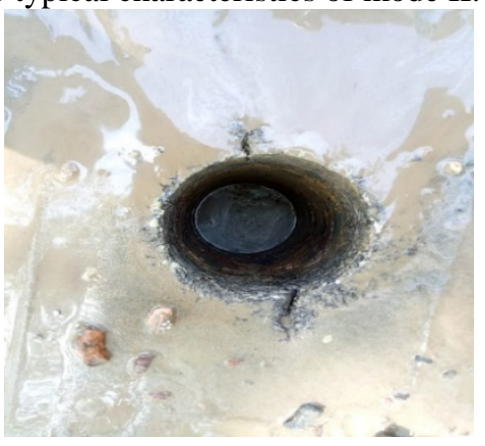

Fig.3 (c) Core Pit 1 


\section{(2) Core sample 2}

The core is taken at the block crack of the road surface and recorded as the core sample 2 . The original road surface condition at the core and core pit taken are shown in figures 4(a) (b). The surface core sample is split at the block crack. The core layer of the base layer is broken, and agglomerates are locally present. Most of the pellets are out of position. The inner wall of the core pit is basically smooth. It can be seen that the damage of the base material is obvious, but the deformation of the road surface is small and the flatness is good. It can be judged that the road damage condition belongs to the transition period of the mode II to the mode III development.

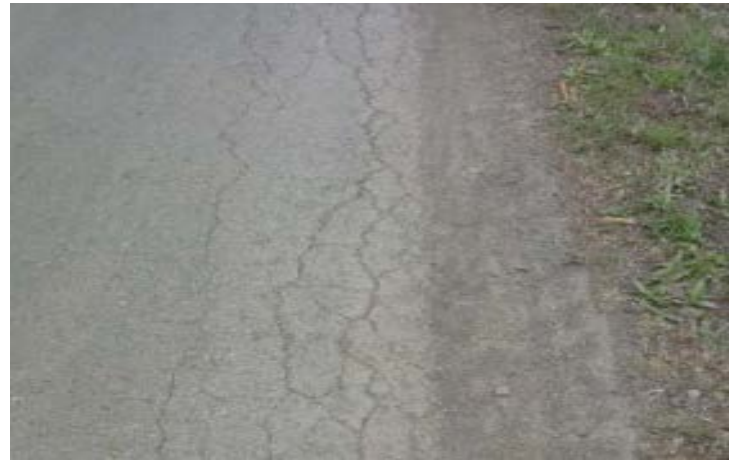

Fig.4 (a) Core sample 2 original pavement

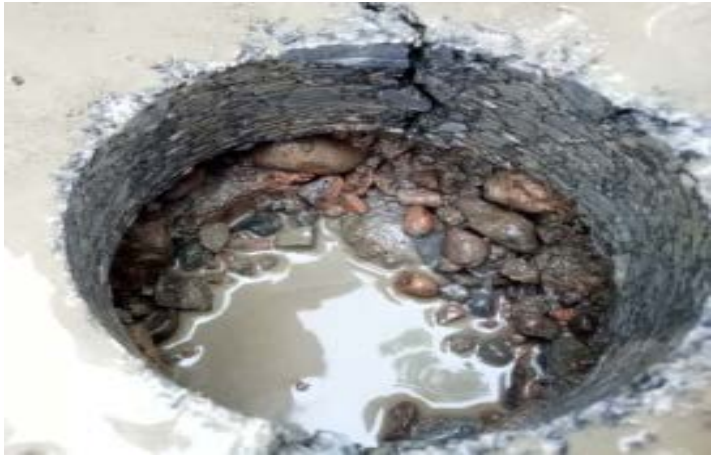

Fig.4 (b) Core sample 2

(3) Core sample 3

Take the core as a sample 3 when the road is intact. The original road surface condition at the core and the core sample and core pit taken are shown in figures $5(\mathrm{a}) \sim(\mathrm{c})$. The core layer of the surface layer is complete, and the core layer of the base layer is intact. The core layer is damaged due to vibration during the core-taking process, and the inner wall of the core pit is smooth. It can be seen that the overall material of the base layer is good, and conforms to the typical characteristics of mode I .

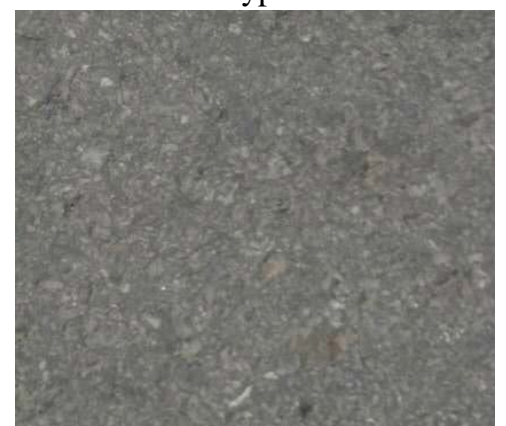

Fig.5 (a) Core sample 3 original pavement

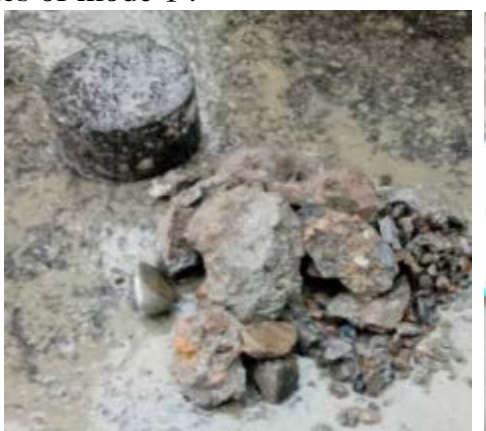

Fig.5 (b) Core sample 3

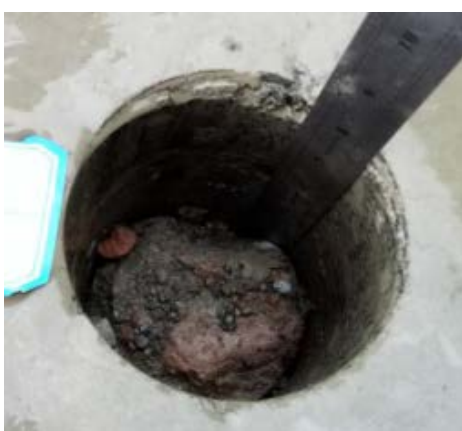

Fig.5 (c) Core Pit 3

It can be seen from the above that the base layer in the investigation section of the Jianhuang line is obviously damaged, and the overall base layer is relatively intact. It belongs to the mode II of the five typical damage modes in the general development period of the rural road asphalt pavement structure damage in Liaoning Province. The evaluation results of the damage condition of asphalt pavement using fuzzy mathematics are consistent with the actual survey results.

\section{Conclusion}

(1) The fuzzy mathematics method was used to evaluate the damage condition of the Jianhuang line asphalt pavement in Benxi City, Liaoning Province, and the evaluation results were consistent with the actual situation. It proves that the asphalt pavement damage condition mode determined by fuzzy mathematics is reliable and operability, and has very good practicability.

(2)In the evaluation of asphalt pavement damage condition, through the field investigation of 300 rural roads in Liaoning Province, the development law of the damage condition of rural road asphalt pavement in Liaoning Province was obtained, and five typical damage modes of the rural road asphalt pavement structure damage during the general development period were proposed. Taking the actual pavement damage investigation result into the calculation model, the damage mode of the pavement damage condition can be obtained, and the damage of the base layer is estimated. The evaluation method is simple and quick and can save money.

(3) The forms of pavement damage are more diverse and each damage form has a correlation. The fuzzy 
mathematics method is used to quantitatively evaluate the indicators with ambiguity, which reduces the influence of subjective factors and ensures the objectivity of the evaluation results.

\section{References}

[1] HU Changbin, WANG Kuili, et al. Research on comprehensive evaluation model of pavement performance maintenance of Shenyang-Dalian expressway. Highway, 2003(3):1-7.

[2] CHEN Zhenhua, YU Yongquan, ZHANG Rui. Research on several models of fuzzy pattern recognition problems. Computer technology and development,2010,20(9):32-35.

[3]LIU Binghan, WANG Weizhi, FANG Xiuduan. A survey of the synergetic algorithm for pattern recognition. Systems engineering and electronics,2003,25(6):758-762.

[4] Wagner T, Bobel FG. Testing synergetic algorithms with industrial classification problems. Neural Networks, 1994, 17(8): 1313- 1321.

[5] SUI Wenbin. Application of Fuzzy Mathematics Method in Comprehensive Evaluation of Water Environment Quality. Journal of Changchun University of Technology,2012,33(4):367-370.

[6] LI Jinlong. Research on the evaluation and prediction and maintenance optimization decision of expressway asphalt pavement performance in Chongqing. Chongqing Jiaotong University,2017.

[7] SHA Qinglin. Early destruction and prevention of expressway asphalt pavement. People Communications Press, 2001.

[8] HU Zhangli, WANG Yu, SU long. Fuzzy comprehensive evaluation of damage condition of asphalt pavement. East China highway,2009,1:20-22.

[9]HAO Changsheng, SHENG Junkun. Optimize mining schemes using analytic hierarchy process and fuzzy mathematics. Journal of Liaoning Technical University,2016,35(7):695-700.

[10] YANG Jun. Vehicle identification based on fuzzy theory. Guangxi Journal of light industry, 2007,3:68-70. 